\title{
Demographical Evaluation of Laparoscopic versus open Appendectomy at Tertiary Care Teaching Hospital
}

\author{
Arshad Hussain Abro, Ahmed Hussain Pathan, Nawaz Ali Dal, Abdul Aziz Laghari, \\ Kamran Hyder Abbasi, Shayan Qasim, Jamrose Durrani
}

\section{ABSTRACT}

OBJECTIVE: To document the demographical evaluation of laparoscopic versus open appendectomy at tertiary care teaching hospital.

PATIENTS AND METHODS: This is comparative study was carried out in Surgical Unit-II, Liaquat University Hospital Jamshoro, Sindh, Pakistan from $21^{\text {st }}$ November 2012 to $3^{\text {rd }}$ February 2016 after the approval from Ethical review committee. During period of the study sixty patients admitted through the outpatient department, as well as from casualty department of Liaquat University Hospital Jamshoro I Hyderabad were enrolled. Results were prepared with the help of tables and graphs. Data was analyzed through SPSS software.

RESULTS: Out of 60 patients, 40 were males (66.66\%) and 20 females (33.33\%); with male to female ratio of 2:1. The mean age for both groups was 26.78 years, ranging from 10 to 70 years. Symptoms of patients in both groups were almost identical comprising of pain in right iliac fossa in $59(98.33 \%)$, pain starting around umbilicus in $45(75 \%)$, nausea in 50(83.33\%), vomiting 35(58.33\%), anorexia in 25 $(41.66 \%)$, fever in $22(36.66 \%)$ and altered bowel habits in $20(33.33 \%)$.

CONCLUSION: The laparoscopic appendectomy has significant advantages over open appendectomy with respect to length of hospital stay, discharge from hospital, and postoperative in-hospital complications \& morbidity.

KEYWORDS: Laparoscopy, Appendectomy, Postoperative complications.

This article may be cited as: Abro AH, Pathan AH, Dal NA, Laghari AA, Abbasi KH, Qasim S, Durrani J. Demographical Evaluation of Laparoscopic Versus Open Appendectomy at Tertiary Care Teaching Hospital. J Liaquat Uni Med Health Sci. 2017;16(01):24-8. doi: $10.22442 /$ jlumhs. 171610501

\section{INTRODUCTION}

The appendix is a small, tube-shaped pouch attached to large intestine and located in the lower right side of abdomen, and appendicitis is the most common cause of surgical abdomen in all age groups. ${ }^{1,2}$ Approximately $7 \%-10 \%$ of the general population develop acute appendicitis with the maximal incidence being in the 2nd and 3rd decades of life; whereas an appendectomy, the surgical removal of the appendix and a common emergency surgery that's performed to treat appendicitis. ${ }^{3-4}$

Briefly, the pathophysiology and progressive timeline of acute appendicitis are attributed as luminal obstruction causing distention, ineffective venous and lymphatic drainage, bacterial invasion and perforation with associated leakage of contents into the peritoneal cavity. ${ }^{5-8}$

Open appendectomy has been the treatment of choice for more than a century and the procedure is standardized among surgeons. ${ }^{9}$ Encouraged by the success of laparoscopic cholecystectomy, which has become the gold-standard treatment for gallstone disease in a short span of time, laparoscopic surgery has gained its popularity and found application in almost every surgical specialty. ${ }^{10-12}$ Laparoscopic appendectomy has been shown to be feasible and safe in randomized comparisons with open appendectomy. ${ }^{13}$ Laparoscopic appendectomy has improved diagnostic accuracy along with advantages in terms of fewer wound infections, less pain, faster recovery and earlier return to normal activity. ${ }^{14}$ On the contrary, laparoscopic appendectomy consumes more operating time and is associated with increased hospital costs. ${ }^{15,16}$

No consensus exists as to whether laparoscopy should be performed in selected patients or routinely for all patients with suspected acute appendicitis. ${ }^{18}$ Keeping in mind this background and the fact that studies comparing laparoscopic and open appendectomy are fewer in developing countries, this observational study was carried out to document the 
demographical evaluation in both procedures in terms of hospital stay, operating time, postoperative pain, morbidity and time to resume normal activity.

\section{PATIENTS \& METHODS}

After approval from research ethical committee, this comparative observational study was carried out in Surgical Unit-II, Liaquat University Hospital Jamshoro, Sindh, Pakistan from $21^{\text {st }}$ November 2012 to $3^{\text {rd }}$ February 2016. Patients admitted through the outpatient and casualty department of Liaquat University Hospital Jamshoro / Hyderabad, diagnosed after pre-operative workup as acute appendicitis $(n=60)$ were enrolled for this study. Clinical history recorded with special regard to the pain in right iliac fossa (RIF), pain starting around umbilicus, nausea, vomiting, fever and altered bowel habits. Clinical examination performed to elicit tenderness at RIF, systemic examination done to exclude any co-morbidity. After base line investigations, ultrasound abdomen done in every case to add in the clinical diagnosis. Patients presenting with features of generalized peritonitis, patients with palpable mass in right iliac fossa and patients with history of previous operation on lower abdomen or cesarean section were not considered for this study. All those selected for this study through purposive non-probability sampling were allotted to two techniques on alternate basis in two groups. Group A for open appendectomy and group B for laparoscopic appendectomy. Follow up of all these patients was done for up to 6 months. All data was entered in a specified proforma designed for this purpose. Data entered and analyzed through SPSS software version 16.0. Results presented as tables and graphs.

\section{RESULTS}

The 60 cases of appendicitis selected for this study were equally distributed to group $A$ where open appendectomy was performed and group B where laparoscopic appendectomy was performed. Out of 60 patients, 40 were male $(66.66 \%)$ and 20 patients were female $(33.33 \%)$; with male to female ratio of $2: 1$ (Table I). The mean age of all patients was 26.78 years ranging from 10 to 70 years. (Table II).

Symptoms of patients in both groups were pain in RIF in $59(98.33 \%)$, pain around umbilicus in $45(75 \%)$, nausea in $50(83.33 \%)$, vomiting $35(58.33 \%)$, anorexia in $25(41.66 \%)$, fever in $22(36.66 \%)$ and altered bowel habits in 20(33.33\%) (Table III)

Operative time in both groups was recorded. Operative time ranged from 30 minutes to 90 minutes in both groups. The mean time in open appendectomy (OA) group was $38.90 \pm S D 15.90$ minutes and for laparoscopic appendectomy (LA) group it was 26.30 \pm SD12.96 minutes. (Table IV). The duration of hospital stay varied from 1 to 4 days. It was longer about 2-3 days in $46(93.33 \%)$ of OA patients as compared to LA cases where majority $30(100 \%)$ were discharged within 2 nd days. The mean hospital stay in OA group was $2.01 \pm 0.90$ days and LA group was $1.07 \pm 0.88$ days. Mild pain was felt in $5(16.66 \%)$ patients of open appendectomy group and 21 (70\%) patients of laparoscopic appendectomy group, Moderate pain was reported by $22(73.33 \%)$ patients of OA group and $9(30 \%)$ patients of laparoscopic appendectomy group, severe pain was described by 3 $(10 \%)$ patients in open appendectomy.

In our study the period of return to normal activity was defined as duration in days post operatively when patient himself or herself felt fit to do routine physical work and it started from day of operation and included the period of hospital stay and period which patient stayed in his or her home. The period of return to normal activity in open appendectomy ranged from 725 days (mean 14.8 days) while in laparoscopic appendectomy it ranged from 7-15 days (mean 9.8 days). The post operative follow up was for up to 6 months.

\section{TABLE I: GENDER DISTRIBUTION}

\begin{tabular}{|c|c|c|c|}
\hline \multicolumn{3}{|c|}{ Gender } \\
\hline Male & \multicolumn{2}{c|}{ Female } \\
\hline No: of Patients & $\%$ Age & No: of Patients & $\%$ Age \\
\hline 40 & $66.66 \%$ & 20 & $33.33 \%$ \\
\hline
\end{tabular}

Male: Female Ratio $=2: 1$

TABLE II: AGE DISTRIBUTION

\begin{tabular}{|c|c|c|}
\hline $\begin{array}{c}\text { Age of patients } \\
\text { Years }\end{array}$ & $\begin{array}{c}\text { No. of patients } \\
(\mathbf{n = 6 0 )}\end{array}$ & $\begin{array}{c}\text { Percentage } \\
\mathbf{( \% )}\end{array}$ \\
\hline $10-20$ years & 14 & $23.33 \%$ \\
\hline $21-30$ years & 26 & $43.33 \%$ \\
\hline $31-40$ years & 6 & $10 \%$ \\
\hline $41-50$ years & 5 & $8.33 \%$ \\
\hline $51-60$ years & 7 & $11.66 \%$ \\
\hline $61-70$ years & 2 & $3.33 \%$ \\
\hline
\end{tabular}

Means Age 26.78 years 
Arshad Hussain Abro, Ahmed Hussain Pathan, Nawaz Ali Dal, Abdul Aziz Laghari, Kamran Hyder Abbasi, Shayan Qasim, et al.

TABLE III: SYMPTOMS OF PATIENTS

\begin{tabular}{|l|c|c|}
\hline \multicolumn{1}{|c|}{$\begin{array}{c}\text { Symptoms of } \\
\text { Patients }\end{array}$} & $\begin{array}{c}\text { No. of patients } \\
(\mathbf{n = 6 0 )}\end{array}$ & $\begin{array}{c}\text { Percentage } \\
(\mathbf{\%})\end{array}$ \\
\hline Pain in RIF & 59 & $98.33 \%$ \\
\hline $\begin{array}{l}\text { Pain starting around } \\
\text { umbilicus }\end{array}$ & 45 & $75 \%$ \\
\hline Nausea & 50 & $83.33 \%$ \\
\hline Vomiting & 35 & $58.33 \%$ \\
\hline Anorexia & 25 & $41.66 \%$ \\
\hline Fever & 22 & $36.66 \%$ \\
\hline Altered bowel habits & 20 & $33.33 \%$ \\
\hline
\end{tabular}

TABLE IV: OPERATIVE TIME

\begin{tabular}{|l|c|c|c|c|}
\hline \multirow{2}{*}{$\begin{array}{c}\text { Operative } \\
\text { time }\end{array}$} & \multicolumn{2}{|c|}{ O.A Group } & \multicolumn{2}{c|}{ L.A Group } \\
\cline { 2 - 5 } & $\begin{array}{c}\text { No: of } \\
\text { Patients }\end{array}$ & $\%$ Age & $\begin{array}{c}\text { No: of } \\
\text { Patients }\end{array}$ & $\%$ Age \\
\hline 30 Minutes & 6 & $16.66 \%$ & 13 & $43.33 \%$ \\
\hline 45 Minutes & 16 & $53.33 \%$ & 10 & $33.33 \%$ \\
\hline 60 Minutes & 5 & $16.66 \%$ & 6 & $20 \%$ \\
\hline 75 Minutes & 2 & $6.66 \%$ & 1 & $3.33 \%$ \\
\hline 90 Minutes & 1 & $3.33 \%$ & 0 & $0 \%$ \\
\hline Total & 30 & $100 \%$ & 30 & $100 \%$ \\
\hline $\begin{array}{l}\text { Mean } \\
\text { Operative Time }\end{array}$ & 38.90 & \multicolumn{2}{c|}{26.30} \\
\hline Std. Deviation & \multicolumn{2}{|c|}{15.924} & \multicolumn{2}{c|}{12.960} \\
\hline
\end{tabular}

\section{DISCUSSION}

Acute appendicitis is the most common surgical condition encountered in emergency room. The first descriptions of the appendix date to the sixteenth century. Although first sketched in the anatomic notebooks of Leonardo da Vinci around year 1500, the appendix was not formally described until 1524 by da Capri and in year1543 by Vesalius. Perhaps the first description of a case of appendicitis was by Fernel in 1554. First recorded appendectomy was performed by Amyand in 1736, when he operated on a boy with an enterocutaneous fistula within an inguinal hernia. On exploration of the hernia sac, he discovered appendix, which had been perforated by a pin resulting in a fecal fistula $^{18}$.

In our study sex ratio showed predominance of male. Out of 60 patients 40 were male $(66.66 \%)$ and 20 female $(33.33 \%)$; with male to female ratio of $2: 1$. However the male to female ratio reported by
Muhammad $\mathrm{A}^{19}$ was 1.3:1.

The age ranged from 10 to 70 years with mean age of 26.78 years. The peak age seen in our study was $2^{\text {nd }}$ and $3^{\text {rd }}$ decade of life which is comparable to the study of Jan $\mathrm{H}$ where peak incidence was seen in the 3rd decade of Life ${ }^{20}$. However Khanzada TW showed age range from 15 to 65 years with a median age of 28 years ${ }^{21}$.

In this study the pain in right iliac fossa was the main presenting symptom seen in 59 (98.33\%) patients, where as other symptoms included pain around umbilicus in $45(75 \%)$, nausea 50(83.33\%), vomiting 35 $(58.33 \%)$, anorexia $25(41.66 \%)$, fever $22(36.66 \%)$ and altered bowel habits in 20(33.33\%) patients. However in study of Soomro $\mathrm{BA}^{22}$ pain in right iliac fossa was found in $98.27 \%$ of patients, anorexia in $86.20 \%$ patients, vomiting $68.96 \%$ and fever in $43.10 \%$ patients.

The clinical parameters were further supported by clinical examination which revealed tenderness at Mc Burney's point in 59 (98.33\%) patients, guarding in 52 $(86.66 \%)$ patients, rebound tenderness in $55(91.66 \%)$ patients and raised body temperature in $20(33.33 \%$ ) of cases. Findings of clinical examination reported by Paulson $\mathrm{EK}^{23}$ et al, includes rebound tenderness in $63 \%$, guarding in 39 to $74 \%$ and raised body temperature in $67 \%$ of cases.

The operative time in this series was significantly longer in open appendectomy group. The mean operative time for open appendectomy group was $38.90 \pm 15.90$ minutes and for laparoscopic appendectomy it was $26.30 \pm 12.96$ minutes with range of 30 to 90 minutes in both groups. The median operative time given by Swank $\mathrm{HA}^{24}$ in the open appendectomy (55 minutes) group was significantly shorter than in the laparoscopic group (70 minutes). This is opposite to present study which shows longer operative time in open appendectomy group as compared laparoscopic appendectomy group.

In our study majority of cases (83.33\%) of open appendectomy group felt moderate to severe pain and late post operative recovery as compared to laparoscopic appendectomy group where $30 \%$ felt mild to moderate pain with quick recovery and early mobilization and therefore less need of postoperative analgesia. These finding are in agreement with the finding reported by $\mathrm{De} \mathrm{U}^{25}$.

In current study the incidence of postoperative complications was higher in open appendectomy as compared to laparoscopic appendectomy group. The wound infection observed in open appendectomy group $(10 \%)$ was almost double than that in laparoscopic appendectomy group (6.66\%). Whereas other complications like abdominal collection open appendectomy (6.66\%) V/S laparoscopic appendectomy $(0.00 \%)$, paralytic lleus open 
appendectomy (3.33\%) V/S laparoscopic appendectomy $(0.00 \%)$, Intestinal obstruction due to adhesion open appendectomy (6.66\%) V/S laparoscopic appendectomy $(0.00 \%)$ and right inguinal hernia open appendectomy (3.33\%) V/S laparoscopic appendectomy $(0.00 \%)$ were also found more in open appendectomy group. However in the study of Marzouk $\mathrm{M}^{26}$ like our study the wound infection was found more in open appendectomy $(7.6 \%)$ than laparoscopic appendectomy $(0.00 \%)$ group whereas Intra abdominal infection was seen higher in laparoscopic appendectomy $(2.7 \%)$ as compared to open appendectomy $(2.5 \%)$ group.

The hospital stay in this study ranged from 1 to 4 days in both groups with mean hospital stay of $2.01 \pm 0.90$ days in open appendectomy group and 1.07 \pm 0.88 days in laparoscopic appendectomy group. It is comparable to other studies given by different authors report median hospital stay of 2-5 days irrespective of laparoscopic or open procedure. Also recent retrospective cohort studies or chart reviews have found shorter hospital stay in laparoscopic appendectomy as compared to open appendectomy. ${ }^{27-30}$

In our study the period of return to normal activity was defined as duration in days postoperatively when patient him or herself felt fit to do routine physical work and it started from day of operation today of return to normal work. The period of return to normal activity in open appendectomy ranged from 7-25 days (mean 14.8 days) while in laparoscopic appendectomy it ranged from 7-15 days (mean 9.8 days). Over all time of return to normal activity and work is shorter in laparoscopic appendectomy as compared to open appendectomy patients as mentioned in earlier studies. $^{31,32}$

\section{CONCLUSION}

We concludes that laparoscopic appendectomy has significant advantages over open appendectomy with respect to length of hospital stay postoperative morbidity, discharge from hospital, and duration of return to normal work. However, to increase confidence, all aspects of laparoscopic appendectomy and open appendectomy must be compared, including postoperative pain, patient's quality of life, days away from work, procedural costs, total costs, and long-term complications must be compared on with large sample size.

\section{ABBREVIATIONS}

LA: Laparoscopic appendectomy

OA: Open appendectomy

RIF: Right iliac fossa.

SD: Standard deviation

SPSS:Statistical Package for the Social Sciences

\section{VS: Versus}

\section{REFERENCES}

1. Agresta F, Ansaloni L, Catena F, et al. Acute appendicitis: position paper, WSES, 2013. World J Emerg Surg. 2014;9(1):26

2. Ruffolo C, Fiorot A, Pagura G, et al. Acute appendicitis: What is the gold standard of treatment? World J Gastroenterol. 2013.;19(47):8799-8807.

3. Garst GC, Moore EE, Banerjee MN, et al. Acute appendicitis: a disease severity score for the acute care surgeon. J Trauma Acute Care Surg.2013;74(1):32-6

4. Drake FT, Flum DR. Improvement in the Diagnosis of Appendicitis. Adv Surg. 2013;47:299-328.

5. Pinto $F$, Pinto A, Russo A, et al. Accuracy of ultrasonography in the diagnosis of acute appendicitis in adult patients: review of the literature. Crit Ultrasound J. 2013;5(Suppl 1):S2-7

6. Asad S, Ahmed A, Ahmad S, et al. Causes of delayed presentation of acute appendicitis and its impact on morbidity and mortality. J Ayub Med Coll Abbottabad. 2015;27(3):620-3.

7. Ahmed MU, Bilal M, Anis K, et al. The Frequency of Enterobius Vermicularis Infections in Patients Diagnosed With Acute Appendicitis in Pakistan. Glob J Health Sci. 2015;7(5):196-201.

8. Jin-Hui Zhu, Wei Li, Kai Yu, et al. New strategy during complicated open appendectomy: Convert open operation to laparoscopy. World J Gastroenterol. 2014 Aug 21;20(31):10938-43.

9. Chung JC, Cho GS, Shin EJ, et al. Clinical outcomes compared between laparoscopic and open appendectomy in pregnant women. Can $\mathrm{J}$ Surg. 2013 Oct; 56(5): 341-46.

10. Ciarrocchi A, Amicucci G. Laparoscopic versus open appendectomy in obese patients: A metaanalysis of prospective and retrospective studies. J Minim Access Surg. 2014 Jan-Mar; 10(1): 4-9.

11. Olijnyk JG, Pretto GG, da Costa Filho OP, et al. Two-port laparoscopic appendectomy as transition to laparoendoscopic single site surgery. J Minim Access Surg. 2014 Jan-Mar; 10(1):23-26.

12. Ein SH, Nasr A, Ein A. Open appendectomy for pediatric ruptured appendicitis: a historical clinical review of the prophylaxis of wound infection and postoperative intra-abdominal abscess. Can J Surg. 2013 Jun; 56(3): E7-E12.

13. Lin HF, Lai H, Lai IR. Laparoscopic treatment of perforated appendicitis. World J Gastroenterol. 2014 Oct 21; 20(39): 14338-47.

14. Gupta N, Machado-Aranda D, Bennett K, Mittal VK . Identification of Preoperative Risk Factors Associated With the Conversion of Laparoscopic to Open Appendectomies. Int Surg. 2013 
Oct-Dec; 98(4): 334-339.

15. Yu G, Han A, Wang W. Comparison of Laparoscopic Appendectomy with open appendectomy in Treating Children with Appendicitis. Pak J Med Sci. 2016;32(2):299-304.

16. Esposito C, Calvo Al, Castagnetti M, et al. Open versus laparoscopic appendectomy in the pediatric population: a literature review and analysis of complications. J Laparoendosc Adv Surg Tech A. 2012 Oct;22(8):834-9.

17. Jaschinski $T$, Mosch $C$, Eikermann $M$, Neugebauer EA. Laparoscopic versus open appendectomy in patients with suspected appendicitis: a systematic review of metaanalyses of randomised controlled trials. BMC Gastroenterol. 2015; 15: 48-53

18. Flood L, Chang KH, McAnena OJ. A rare case of Amyand's hernia presenting as an enterocutaneous fistula. JSCR 2010;7:6.

19. Mohammad A, Inam M, Khan M, Iqbal MJ. Usefulness and limitations of modified alvarado scoring system in diagnosis of acute appendicitis. JPMI 2007;21(4):242-7.

20. Jan $\mathrm{H}$, Khan J. Evaluation of modified Alvarado score in the diagnosis of acute appendicitis. Pak J Surg 2007;23(4):248-50.

21. Khanzada TW, Samad A, Sushel C. Negative Appendectomy Rate: Can It be reduced? JLUMHS 2009;8(1):19-22.

22. Soomro BA. Acute appendicitis in children. J Surg Pak Int 2008;13(4):151-4.

23. Paulson EK, Kalady MF, Pappas TN. Clinical Practice. Suspected Appendicitis. N Engl J Med 2003;348(3):236-42.

24. Swank HA, Eshuis EJ, Henegouwen MIB, Bemelman WA. Short- and Long-Term Results of Open
Versus Laparoscopic Appendectomy. World J Surg 2011;35(6):1221-26.

25. De U. Laparoscopic versus open appendectomy: An Indian perspective. J Min Access Surg 2005;1:15-20.

26. Marzouk M, Khater M, Elsadek M, Abdelmoghny A. Laparoscopic vs open appendectomy. A prospective comparative study of 227 patients. Surg Endosc 2003;17: 721-4.

27. Tiwari MM, Reynoso JF, Tsang AW, Oleynikov D. Comparison of outcomes of laparoscopic and open appendectomy in management of uncomplicated and complicated appendicitis. Ann Surg. 2011 Dec;254(6):927-32.

28. Biondi A, Stefano CA, Ferrara F, et al. Laparoscopic versus open appendectomy: a retrospective cohort study assessing outcomes and costeffectiveness. World J Emerg Surg. 2016;11(1): 44.

29. Wang CC, Tu CC, Wang PC, et al. Outcome comparison between laparoscopic and open appendectomy: evidence from a nationwide populationbased study. PLoS One. 2013 Jul 12;8(7):68-72.

30. Ali R, Khan MR, Pishori T, et al. Laparoscopic Appendectomy for Acute Appendicitis: Is This a Feasible Option for Developing Countries?. Saudi J Gastroenterol. 2010 Jan-Mar; 16(1): 25-29.

31. Markar SR, Blackburn S, Cobb R, et al. Laparoscopic Versus Open Appendectomy for Complicated and Uncomplicated Appendicitis in Children. J Gastrointest Surg.2012;16(10):1993-2004

32. Ohtani H, Tamamori $Y$, Arimoto $Y$. Meta-analysis of the Results of Randomized Controlled Trials that Compared Laparoscopic and Open Surgery for Acute Appendicitis. J Gastrointest Surg. 2012;16(10):1929-34.
AUTHOR AFFILIATION:

Dr. Arshad Hussain Abro (Correspondence Author)

Assistant Professor, Department of Surgery

Liaquat University of Medical \& Health Sciences

(LUMHS), Jamshoro, Sindh-Pakistan.

Email: drahabro@hotmail.com

Dr. Ahmed Hussain Pathan

Assistant Professor, Department of Surgery

LUMHS, Jamshoro, Sindh-Pakistan.

Dr. Nawaz Ali Dal

Senior Registrar, Department of Surgery

LUMHS, Jamshoro, Sindh-Pakistan.
Prof. Abdul Aziz Laghari

Professor, Department of Surgery

LUMHS, Jamshoro, Sindh-Pakistan.

Dr. Kamran Hyder Abbasi

PG, Department of Surgery

LUMHS, Jamshoro, Sindh-Pakistan.

Dr. Shayan Qasim

Brandon Regional Hospital, Brandon, Florida.

Dr. Jamrose Durrani

LUMHS, Jamshoro, Sindh-Pakistan. 